\title{
High Baseline Lipoprotein(a) Level as a Risk Factor for Coronary Artery Calcification Progression: Sub-analysis of a Prospective Multicenter Trial
}

\author{
Jun Ida $^{a}$, Kazuhiko Kotani ${ }^{b}$, Toru Miyoshi $^{a *}, K^{a z u f u m i}$ Nakamura ${ }^{a *}$, \\ Kunihisa Kohno $^{a}$, Hirohiko Asonuma ${ }^{c}$, Satoru Sakuragi ${ }^{d}$, Masayuki Doi ${ }^{e}$, \\ Takashi Miki $^{a}$, Yasushi Koyama ${ }^{f}$, and Hiroshi Ito ${ }^{a}$
}

${ }^{a}$ Department of Cardiovascular Medicine, Okayama University Graduate School of Medicine, Dentistry and Pharmaceutical Sciences, Okayama 700-8558, Japan, ${ }^{b}$ Department of Clinical Laboratory Medicine, Department of Community and Family Medicine, Jichi Medical University, Shimotsuke, Tochigi 329-0498, Japan,

${ }^{c}$ Department of Cardiology, Kasaoka Diichi Hospital, Kasaoka, Okayama 714-0043, Japan,

${ }^{d}$ Department of Cardiology, Iwakuni Clinical Center, Iwakuni, Yamaguchi 740-8510, Japan,

${ }^{e}$ Department of Cardiology, Kgawa Prefectural Central Hospital, Takamatsu 760-8557, Japan,

${ }^{f}$ Department of Cardiology, Sakurabashi Watanabe Hospital, Osaka 530-0001, Japan

\begin{abstract}
Lipoprotein(a), or $\operatorname{Lp}(\mathrm{a})$, is a low-density lipoprotein-like particle largely independent of known risk factors for, and predictive of, cardiovascular disease (CVD). We investigated the association between baseline $\mathrm{Lp}(\mathrm{a})$ levels and the progression of coronary artery calcification (CAC) in patients with hypercholesterolemia undergoing statin therapy. This study was a sub-analysis of a multicenter prospective study that evaluated the annual progression of CAC under intensive and standard pitavastatin treatment with or without eicosapentaenoic acid in patients with an Agatston score of 1 to 999, and hypercholesterolemia treated with statins. We classified the patients into 3 groups according to CAC progression. A total of 147 patients (mean age, 67 years; men, 54\%) were analyzed. The proportion of patients with $\mathrm{Lp}(\mathrm{a})>30 \mathrm{mg} / \mathrm{dL}$ significantly increased as CAC progressed (non-progression; $5.4 \%, 0<$ CAC progression $\leqq 100 ; 7.7 \%$, and CAC progression $>100 ; 23.6 \%$ ). Logistic regression analysis showed that $\operatorname{Lp}(\mathrm{a})>30 \mathrm{mg} / \mathrm{dL}$ was an independent predictor of the annual change in Agatston score $>100$ (OR: $5.51 ; 95 \%$ CI: 1.28-23.68; $p=0.02$ ), even after adjusting for age, sex, hypertension, diabetes mellitus, current smoking, body mass index, and lipid-lowering medications. Baseline $\operatorname{Lp}(\mathrm{a})$ $>30 \mathrm{mg} / \mathrm{dL}$ was a predictor of CAC progression in this population of patients with hypercholesterolemia undergoing statin therapy.
\end{abstract}

Key words: lipoprotein(a), coronary artery calcification, statins, hypercholesterolemia

$\mathrm{L}$ ipoprotein(a), or $\mathrm{Lp}(\mathrm{a})$, is a low-density lipoprotein (LDL)-like particle. Apolipoprotein B is covalently linked to apolipoprotein(a) by a single disulfide bond [1]. Circulating concentrations of $\mathrm{Lp}(\mathrm{a})$ vary

Received September 15, 2017; accepted October 30, 2017.

*Corresponding author. Phone : +81-86-235-7351; Fax :+81-86-235-7353

E-mail: miyoshit@cc.okayama-u.ac.jp (T. Miyoshi) or ichibun@cc.okayama-u.ac.jp (K. Nakamura) widely across individuals and ethnic subgroups, mediated in large part by genetic variations at the LPA gene locus [2]. A meta-analysis of 126,634 participants in 36 prospective studies found that $\operatorname{Lp}(\mathrm{a})$ was an independent risk factor for coronary heart disease and stroke [3]. Mendelian randomization studies have linked

Conflict of Interest Disclosures: No potential conflict of interest relevant to this article was reported. 
genetic variations at the LPA locus to both circulating $\mathrm{Lp}$ (a) concentrations and the risk for cardiovascular disease (CVD), supporting a causal role of $L p(a)$ in CVD pathogenesis $[4,5]$. Generic methods to modulate circulating $\mathrm{Lp}(\mathrm{a})$ concentrations in daily practice remain to be determined, and the further accumulation of evidence based on the monitoring of patients with high $\mathrm{Lp}(\mathrm{a})$ levels (even when undergoing treatment with lipid-lowering drugs such as statins) is crucial $[2,6]$.

Among the methods available for the assessment of CVD risk, coronary artery calcification (CAC), which is determined by computed tomography (CT), is an excellent marker for the clinical measurement of the burden of CVD risk [7]. Detrano et al. reported that the adjusted risk for a coronary event increased by a factor of 9.67 among participants with CAC scores $>300$ compared to participants with no coronary calcification [8]. After serial assessments, the progression of CAC scores has been proposed as a useful predictor of cardiac outcome [9-11].

We recently reported the results of a prospective multicenter study (Effect of pitavastatin and EPA on coronary artery calcification detected by computed tomography: PEACH study) that examined the effects of intensive and standard pitavastatin treatment with or without eicosapentaenoic acid (EPA) on the annual progression of CAC [12]. In that study, we found that the overall CAC progression rate over 1 year was $40 \%$ and that the $\mathrm{CAC}$ progression in each patient group was not affected by the allocated treatments. A determination of the factors involved in CAC progression is of interest.

Cross-sectional studies have reported an association between $\operatorname{Lp}(\mathrm{a})$ and CAC $[13,14]$. Data from a large Asian cohort of 14,583 participants suggested a robust association between higher Lp(a) level and CAC in both men and women, regardless of LDL cholesterol level and other CVD risk factors [14]. However, that study was limited by the nature of cross-sectional studies with regard to causality. Longitudinal studies (including short-term studies) are required to confirm the progression of CAC using baseline Lp(a) levels. In the present study, we analyzed the association between baseline $\mathrm{Lp}(\mathrm{a})$ levels and the annual progression of CAC in patients with hypercholesterolemia who were undergoing statin therapy.

\section{Methods}

Ethical considerations. The principal study was a prospective, open-label, multicenter trial conducted between May 2010 and August 2011. That study was approved by the Ethics Committee of Okayama University Graduate School of Medicine, Dentistry, and Pharmaceutical Sciences (Certificate No. 1652) and other hospitals involved. All participants provided written informed consent before enrolling. The study was conducted in accord with the principles contained within the Declaration of Helsinki. The study is registered at the UMIN Clinical Trials Registry (UMIN000003171; Effect of pitavastatin and EPA on coronary artery calcification detected by computed tomography: PEACH study).

Study design. The current study was a pre-specified sub-analysis of the PEACH study [12]. Eligible patients were adults ( $>20$ years old) with an Agatston score of 1 to 999, with hypercholesterolemia (LDL cholesterol $\geq 140 \mathrm{mg} / \mathrm{dL}$ at screening or taking a statin), and no history of CVD. The exclusion criteria were a history of coronary revascularization, including percutaneous coronary intervention and coronary artery bypass surgery; Agatston score of 0 or $>1,000$; familial hypercholesterolemia; use of cyclosporine; and use of lipid-lowering agents excluding statins. Patients were enrolled after an evaluation for eligibility at each institution, including baseline multi-detector row computed tomography (MDCT) image acquisition. The participants were randomly allocated into 3 groups: the pitavastatin $2 \mathrm{mg} /$ day, pitavastatin $4 \mathrm{mg} /$ day, or pitavastatin $2 \mathrm{mg} /$ day combined with EPA 1,800 mg/ day groups. After taking pitavastatin $2 \mathrm{mg}$ /day for 2 months to check for tolerance, the allocated treatment was started.

Baseline blood test data were obtained just before the allocated treatment was started. MDCT and blood tests were performed again at the 1-year follow-up. Figure 1 is a flow diagram of the study design. In the principal study, we enrolled 217 patients at 27 centers in Japan. Among them, 157 patients were included in the primary analysis. Ten patients were excluded because their stored blood samples were not available for the measurement of $\mathrm{Lp}(\mathrm{a})$. A final total of 147 patients were included in this post-hoc analysis. The primary outcome of the sub-study was the association between the patients' baseline Lp(a) level and their annual CAC pro- 


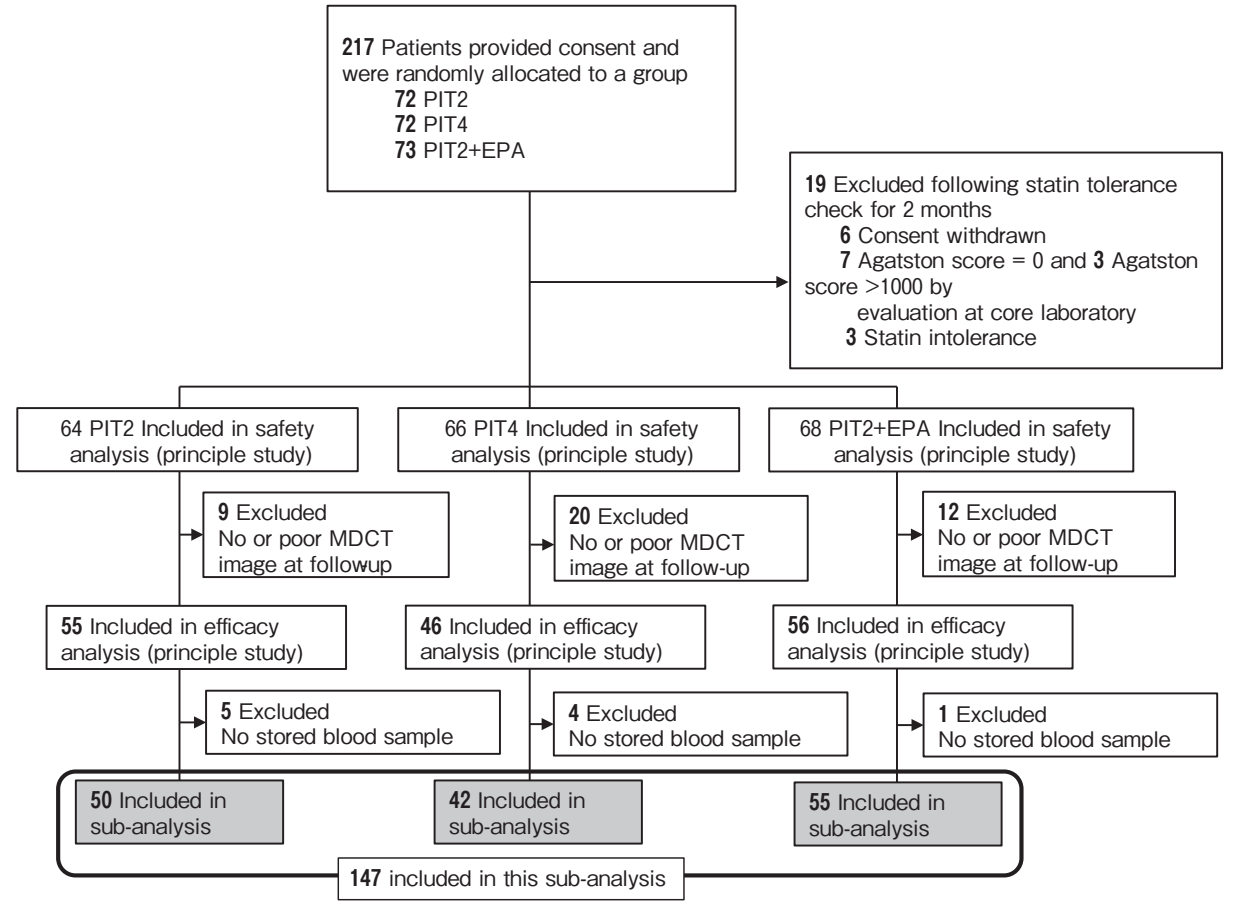

Fig. 1 Flow diagram of patient enrollment. PIT2, pitavastatin $2 \mathrm{mg} /$ day; PIT4, pitavastatin $4 \mathrm{mg} /$ day; EPA, eicosapentaenoic acid $1,800 \mathrm{mg} /$ day; MDCT, multidetector row computed tomography. gression (Agatston score).

MDCT imaging and CAC analysis. MDCT imaging was performed as described [15]. All recruiting sites had previous cardiac CT experience and were equipped with 64-slice or higher advanced CT technology. ECG triggering was performed at $80 \%$ of the RR interval. MDCT images were documented in a digital imaging and communications in medicine (DICOM) format, which was sent to the core laboratory at L\&L Co. (Osaka, Japan) for blinded analysis. The local sites generated the total Agatston score, which was used as the inclusion criterion of this study. A calcium threshold $\geq 130$ Hounsfield units was used. As described by Agatston, the calcium score was determined by multiplying the area of each calcified lesion by a weighing factor corresponding to the peak pixel intensity for each lesion [16].

The image analysis was performed by a trained radiologist and trained cardiologist (Y.K.) who were blind to the patients' data. Disagreements in data analysis between the 2 observers were resolved by consensus. We divided the participants into three groups according to the severity of CAC progression over 1 year: no progression, $0<\mathrm{CAC}$ progression $\leq 100$, and CAC progression $>100$. CAC progression was defined as any $\mathrm{CAC}$ increase over the year.
Risk factors and laboratory analyses. Data on demographics, smoking status, and medication were collected for each participant. Current smoking was defined as a history of cigarette smoking during the past year. Diabetes was confirmed according to the criteria of the American Diabetes Association [17] or based on a history of diabetes mellitus treatment. Hypertension was defined as having a seated blood pressure of $\geq 140 / 90 \mathrm{mmHg}$ or undergoing treatment with antihypertensive medication. Body mass index (BMI) was calculated as body weight $(\mathrm{kg})$ divided by squared height (m).

All laboratory values were determined at an independent central study laboratory (SRL, Tokyo, Japan). Standard enzymatic methods were used to measure total cholesterol, high-density lipoprotein (HDL) cholesterol, LDL cholesterol, and triglycerides. Highsensitivity C-reactive protein levels were determined using an assay (Roche-Hitachi; Hitachi, Tokyo, Japan). Residual serum was separated and stored at $-80^{\circ} \mathrm{C}$, and the serum concentration of $\mathrm{Lp}(\mathrm{a})$ was measured using an enzyme-linked immunosorbent assay (Shino-Test, Tokyo, Japan) [18].

Statistical analysis. Continuous variables are mean (standard deviation) or median (25th percentile, 75 th percentile), as appropriate. Categorical variables 
are frequency and proportion (\%). The Kruskal-Wallis test was used to compare continuous variables among the groups. The chi-square test was used to compare categorical variables. Pearson's correlation coefficients were used to assess relationships between $\operatorname{Lp}(\mathrm{a})$ and other parameters. Data that were not normally distributed, as determined by the Kolmogorov-Smirnov test, were logarithmically transformed before linear regression analysis. Logistic analysis was performed to determine the odds ratio (OR) with $95 \%$ confidence intervals $(95 \% \mathrm{CI})$ for the progression of CAC associated with baseline $\mathrm{Lp}(\mathrm{a})$ level ( $>30 \mathrm{mg} / \mathrm{dL}$ and $\leq 30 \mathrm{mg} / \mathrm{dL}$ ). The following variables were entered into the logistic model: age, sex, hypertension, diabetes mellitus, current smoking, BMI, and lipid-lowering medications (pitavastatin $2 \mathrm{mg} /$ day, pitavastatin $4 \mathrm{mg} /$ day, or pitavastatin $2 \mathrm{mg} /$ day combined with EPA $1,800 \mathrm{mg} /$ day). A $p$-value $<0.05$ was considered significant. Statistical analyses were performed using SPSS 27.0 for Windows (IBM, Armonk, NY, USA).

\section{Results}

Baseline characteristics. Table 1 summarizes the baseline characteristics of participants. The mean age was 67 years, and 54\% were men. The proportions of patients with hypertension and diabetes mellitus were $81 \%$ and $27 \%$, respectively. The median baseline Lp(a)

Table 1 Patient characteristics

\begin{tabular}{lr}
\hline & $\mathrm{n}=147$ \\
\hline Age (years) & $67(10)$ \\
Sex: men, n (\%) & $80(54)$ \\
BMI (kg/m²) & $25.0(4.0)$ \\
Hypertension, n (\%) & $118(81)$ \\
Diabetes mellitus, n (\%) & $39(27)$ \\
Current smoking, n (\%) & $22(15)$ \\
Lp(a) (mg/dL) & $5.7(0.7)$ \\
Hemoglobin A1c (\%) & $117(89,165)$ \\
Triglycerides (mg/dL) & $93.6(24.3)$ \\
LDL cholesterol (mg/dL) & $55.5(13.7)$ \\
HDL cholesterol (mg/dL) & $0.77(0.68,0.90)$ \\
Serum creatinine (mg/dL) & $0.054(0.031,0.106)$ \\
hsCRP (mg/L) & $96(25,244)$ \\
Agatston score & \\
\hline Data are mean (std. dev.), number (\%), or median (25th, 75 th \\
percentiles), as appropriate. Lp(a), lipoprotein a; LDL, low-density \\
lipoprotein; HDL, high-density lipoprotein; hsCRP, high-sensitivity \\
C-reactive protein.
\end{tabular}

level was $10.2 \mathrm{mg} / \mathrm{dL}$, and $9.5 \%$ of participants $(\mathrm{n}=14)$ had an $\mathrm{Lp}(\mathrm{a})$ level $>30 \mathrm{mg} / \mathrm{dL}$.

Association between metabolic parameters and baseline Lp(a) levels. A bivariate correlation analysis with baseline $\operatorname{Lp}(\mathrm{a})$ and other metabolic parameters showed that age was positively correlated with the baseline $\mathrm{Lp}(\mathrm{a})$ level, and the triglycerides level was negatively correlated with the baseline Lp(a) level (Table 2). There was no correlation between the baseline $\mathrm{Lp}(\mathrm{a})$ level and CAC scores.

Comparison of variables according to CAC progression. At the 1-year follow-up, 110 patients (75\%) showed CAC progression. When we compared baseline parameters among the groups with no CAC progression, $0<\mathrm{CAC}$ progression $\leq 100$, and $\mathrm{CAC}$ progression $>100$, it was revealed that the proportion of patients with diabetes mellitus was significantly increased and the LDL cholesterol levels were significantly decreased as the severity of CAC progression increased (Table 3 ). The $\mathrm{Lp}$ (a) levels in patients with no progression, $0<$ CAC progression $\leq 100$, and CAC progression $>100$ were $11.6(6.8,17.2), 8.6(5.0,20.3)$, and 13.1 (4.1, $40.4)$, respectively, and did not differ significantly among the groups $(p=0.23$; Kruskal-Wallis test) (Fig. 2A). The proportion of patients with $\mathrm{Lp}(\mathrm{a})$ $>30 \mathrm{mg} / \mathrm{dL}$ in patients with CAC progression was significantly greater than those of the other groups (no progression; 5.4\%, $0<\mathrm{CAC}$ progression $\leq 100 ; 7.7 \%$, and CAC progression $>100 ; 26.3 \%, p=0.03$ ) (Fig. 2B).

Association between baseline $L p(a)$ and CAC progression. The logistic analysis showed that the odds

Table 2 Correlation between baseline $\mathrm{Lp}(\mathrm{a})^{*}$ and other parameters

\begin{tabular}{lcr}
\hline & $r$ & $p$-value \\
\hline Age & 0.281 & 0.001 \\
BMI & -0.106 & 0.208 \\
Fasting blood glucose & -0.178 & 0.033 \\
Hemoglobin A1c & -0.06 & 0.530 \\
Total cholesterol & -0.021 & 0.804 \\
Triglycerides* & -0.218 & 0.008 \\
HDL cholesterol & 0.06 & 0.492 \\
LDL cholesterol & -0.009 & 0.915 \\
Serum creatinine & -0.089 & 0.287 \\
hsCRP* & 0.015 & 0.853 \\
Agatston score* & 0.124 & 0.136
\end{tabular}

*Lp(a), triglycerides, hsCRP, and Agatston score were log-transformed. 
Table 3 Comparison of variables among patients with CAC progression over a 1-year period

\begin{tabular}{|c|c|c|c|c|}
\hline & $\begin{array}{l}\text { No progression } \\
\quad(n=37)\end{array}$ & $\begin{array}{c}0<\text { CAC progression } \leq 100 \\
(n=91)\end{array}$ & $\begin{array}{l}\text { CAC progression }>100 \\
(n=19)\end{array}$ & $p$-value \\
\hline Age (years) & $66.3(9.4)$ & $67.1(10.2)$ & $68.7(7.1)$ & 0.68 \\
\hline Sex: men, n (\%) & $20(54)$ & $45(49)$ & $15(79)$ & 0.06 \\
\hline $\mathrm{BMI}\left(\mathrm{kg} / \mathrm{m}^{2}\right)$ & $25.9(4.7)$ & $24.9(3.7)$ & $23.9(3.4)$ & 0.26 \\
\hline Diabetes mellitus, n (\%) & $8(22)$ & $21(23)$ & $10(53)$ & 0.02 \\
\hline Hypertension, $\mathrm{n}(\%)$ & $30(81)$ & $74(81)$ & $14(74)$ & 0.74 \\
\hline Current smoking, n (\%) & $8(22)$ & $12(13)$ & $2(11)$ & 0.41 \\
\hline Systolic BP (mmHg) & $134.7(21.5)$ & $131.0(16.5)$ & $131.8(19.8)$ & 0.68 \\
\hline Diastolic BP (mmHg) & $76.4(12.9)$ & $74.4(10.8)$ & $73.5(10.8)$ & 0.74 \\
\hline Hemoglobin A1c (\%) & $5.7(0.6)$ & $5.7(0.7)$ & $6.0(1.0)$ & 0.26 \\
\hline Total cholesterol (mg/dL) & $182.8(30.9)$ & $175.9(30.9)$ & $166.5(31.6)$ & 0.23 \\
\hline LDL cholesterol (mg/dL) & $101.4(24.5)$ & $93.1(22.7)$ & $80.7(26.8)$ & 0.01 \\
\hline Triglycerides (mg/dL) & $123(92,128)$ & $108(84,165)$ & $141(89,155)$ & 0.63 \\
\hline HDL cholesterol (mg/dL) & $53.5(12.4)$ & $56.4(14.6)$ & $54.8(11.5)$ & 0.70 \\
\hline Serum creatinine (mg/dL) & $0.78(0.69,0.86)$ & $0.78(0.63,0.90)$ & $0.76(0.71,0.98)$ & 0.68 \\
\hline $\mathrm{hsCRP}(\mathrm{mg} / \mathrm{dL})$ & $0.054(0.034,0.123)$ & $0.051(0.025,0.105)$ & $0.070(0.038,0.115)$ & 0.58 \\
\hline
\end{tabular}

Data are mean (std. dev.), number (\%), or median (25th, 75 th percentiles), as appropriate.
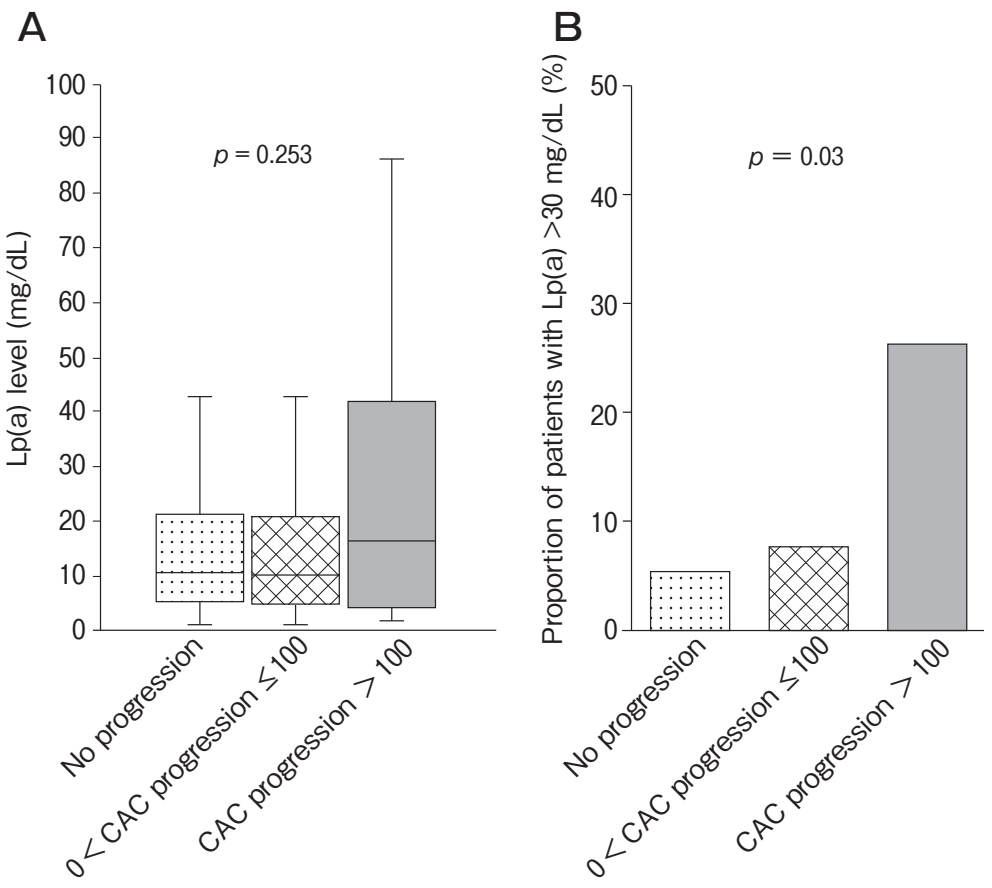

Fig. 2 Comparison of lipoprotein (Lp(a)) levels $(A)$ and the proportion of patients with high $L p(a)(B)$ among the groups classified by coronary artery calcification (CAC) progression severity over 1 year.

Table 4 Odds ratios (95\% confidence intervals) for coronary artery calcification progression $>100$ according to baseline $L p(a)$ levels

\begin{tabular}{lcccc}
\hline & Model 1 & Model 2 & Model 3 & Model 4 \\
\hline $\mathrm{Lp}(\mathrm{a}) \leq 30 \mathrm{mg} / \mathrm{dL}$ & Reference & Reference & Reference & Reference \\
$\mathrm{Lp}(\mathrm{a})>30 \mathrm{mg} / \mathrm{dL}$ & $4.72(1.39-16.08), p=0.01$ & $6.84(1.90-32.16), p<0.01$ & $5.59(1.31-23.81), p=0.01$ & $5.51(1.28-23.68), p=0.02$
\end{tabular}

Model 1, no adjustment: Model 2, adjusted for age and sex: Model 3, Model 2+hypertension, diabetes mellitus, current smoking, and BMl: Model 4, Model 3+lipid-lowering medications. 
ratio of natural log-transformed $\mathrm{Lp}(\mathrm{a})$ for the annual progression of CAC $>100$ was not significant (OR: 1.49, 95\%CI: $0.88-2.53, p=0.13)$. When the risk for annual CAC progression $>100$ according to baseline $\mathrm{Lp}(\mathrm{a})$ level higher or lower than $30 \mathrm{mg} / \mathrm{dL}$ was calculated (Table 4), the patients with an $\mathrm{Lp}(\mathrm{a})$ level $>30 \mathrm{mg} / \mathrm{dL}$ showed a significantly increased risk for CAC progression compared to the patients with an $\mathrm{Lp}(\mathrm{a})$ level $\leq 30 \mathrm{mg} / \mathrm{dL}$ in the crude model (OR: 4.72, 95\%CI: 1.39-16.08; Model 1) and after adjusting for all confounding variables (OR: 5.51, 95\%CI: 1.28-23.68; Model 4).

\section{Discussion}

This study is the first to report an association between the baseline Lp(a) level and CAC progression over a 1-year follow-up in patients with hypercholesterolemia and undergoing statin therapy. Patients with CAC progression $>100$ over the 1-year follow-up showed a greater proportion of high baseline Lp(a) compared to those who had no progression or CAC progression < 100 with LDL cholesterol lower than $100 \mathrm{mg} / \mathrm{dL}$ with statin therapy. The logistic analysis revealed that a baseline $\mathrm{Lp}(\mathrm{a})$ level $>30 \mathrm{mg} / \mathrm{dL}$ presented a 6.84-fold increased risk for CAC progression $>100$ compared to the $\mathrm{Lp}(\mathrm{a})$ levels $\leq 30 \mathrm{mg} / \mathrm{dL}$.

Our present findings are considered complementary to a recent sub-analysis of the JUPITER (Justification for the use of statin in prevention: An intervention trial evaluating rosuvastatin) trial, which reported that higher $\mathrm{Lp}(\mathrm{a})$ concentrations were associated with an increased risk for CVD events under statin therapy [19]. That sub-analysis reported that rosuvastatin reduced the incidence of CVD with no interaction which baseline Lp(a) levels. In the present study, the LDL cholesterol levels in the patients with CAC progression $>100$ were lower than those in the patients with CAC progression $\leq 100$. Taken together, our findings suggest that the $\mathrm{Lp}$ (a) level may be a significant risk factor for CVD events in people with a low LDL cholesterol level undergoing statin therapy. This suggestion also has important clinical implications with regard to assessments (for instance, using CAC) used to identify patients with a high $\operatorname{Lp}(\mathrm{a})$ level. This is because generic methods for modulating circulating $\mathrm{Lp}(\mathrm{a})$ concentrations in daily practice remain to be determined, and careful monitoring of patients with a high $\operatorname{Lp}(\mathrm{a})$ level is needed.
In terms of a clinical cutoff point for $\operatorname{Lp}(\mathrm{a})$, the 2016 Canadian Cardiovascular Society Guidelines for the Management of Dyslipidemia consider Lp(a) $>30 \mathrm{mg} / \mathrm{dL}$ to be a risk factor, and those guidelines suggest measuring $\mathrm{Lp}(\mathrm{a})$ to inform decision-making, particularly in patients at intermediate risk and those with a family history of premature CAD, and in younger patients [20]. A large meta-analysis showed an inflection for risk of myocardial infarction at $\mathrm{Lp}(\mathrm{a})>30 \mathrm{mg} / \mathrm{dL}$ [3]. Data from the Multi-Ethnic Study of Atherosclerosis (MESA) reported that cutoff values of $L p(a)$ for identifying the risk of CVD events differ among races, from $30 \mathrm{mg} / \mathrm{dL}$ to $50 \mathrm{mg} / \mathrm{dL}$ [21]. Tsimikas reported that $\mathrm{Lp}(\mathrm{a})$ levels are skewed leftward, and most individuals (approx. $70 \%$ ) have values in the normal range of $<30 \mathrm{mg} / \mathrm{dL}$ [22].

In the present study, the median $\operatorname{Lp}(\mathrm{a})$ value was $10.2 \mathrm{mg} / \mathrm{dL}$, and the proportion of patients with $\mathrm{Lp}(\mathrm{a})$ $>30 \mathrm{mg} / \mathrm{dL}$ and $>40 \mathrm{mg} / \mathrm{dL}$ were $9.5 \%$ and $3.4 \%$, respectively. Considering these results, we used $\mathrm{Lp}(\mathrm{a})$ $>30 \mathrm{mg} / \mathrm{dL}$ as the cutoff value for the high Lp(a) level, and we observed that high $\mathrm{Lp}(\mathrm{a})$ was a significant risk factor for CAC progression. However, the appropriate cutoff value for Asian populations should be determined by further studies.

The mechanisms underlying the association between elevated Lp(a) and the development of CAC remain unclear. Elevated $\mathrm{Lp}(\mathrm{a})$ may lead to atherosclerosis when particles become trapped within the arterial intima, and may also serve as a carrier of oxidized phospholipids by apolipoprotein B 100, which may propagate atherosclerosis via inflammatory pathways [23]. In addition, it was reported that $\mathrm{Lp}(\mathrm{a})$ and oxidized phospholipids mediate macrophage apoptosis in endoplasmic reticulum-stressed macrophages by signaling through the CD36/Toll-like receptor 2 pathway [24]. We thus speculate that $\mathrm{Lp}(\mathrm{a})$ may contribute to CAC through the development of atherosclerosis via multiple pathways.

In this study, the patients with baseline $\mathrm{Lp}(\mathrm{a})$ $>30 \mathrm{mg} / \mathrm{dL}$ showed a significantly increased risk for CAC progression with low LDL cholesterol and undergoing statin therapy. CAC incidence and progression is considered an excellent surrogate marker for the prediction of CVD risk [7]. A cross-sectional study of an Asian population reported that $\operatorname{Lp}(\mathrm{a})$ levels were positively associated with CAC score [14]. However, that was a cross-sectional study and it therefore could not 
show a causal relationship between $\operatorname{Lp}(\mathrm{a})$ and CAC progression. Recent data from a health checkup program suggest that people with a baseline Lp(a) level $\geq 50 \mathrm{mg} /$ $\mathrm{dL}$ have a 1.33-fold increased risk for CAC progression compared to those with an $\mathrm{Lp}(\mathrm{a})$ level $<50 \mathrm{mg} / \mathrm{dL}$ [25]. The present study is the first longitudinal study to evaluate the association between baseline $\operatorname{Lp}(\mathrm{a})$ and CAC progression in patients with hypercholesterolemia undergoing statin therapy.

This study has several limitations. First, as the study was of people with hypercholesterolemia undergoing statin therapy, the results cannot be applied to the general population. Second, although the Agatston score as a marker for quantifying CAC is an excellent surrogate marker for the prediction of CVD, we analyzed only CAC progression as the endpoint, not actual CVD events. We thus cannot conclude that there is an association between high $\mathrm{Lp}(\mathrm{a})$ and CVD events. Third, the duration of follow-up was 1 year, and a longer follow-up period might reveal a difference in the impact of $\mathrm{Lp}$ (a) on the progression of CAC. In addition, data on coronary CT angiography were not available in this study. Fourth, changes in plaque volumes and morphology could not be evaluated. Finally, the relationship between the change in $\operatorname{Lp}(\mathrm{a})$ and the change in CAC remains unclear. Prospective studies for evaluating the effect of lowering $\operatorname{Lp}(\mathrm{a})$ on the progression of $\mathrm{CAC}$ are warranted to address this issue.

In, conclusion, high $\mathrm{Lp}(\mathrm{a})$ played a role in CAC progression in this population of patients with hypercholesterolemia undergoing statin therapy. Our findings suggest that measuring $\operatorname{Lp}(\mathrm{a})$ levels will help in the risk assessment for CVD events as well as treatment options.

Acknowledgments. We thank Takefumi Oka, MD, Tadahisa Uesugi, MD, Makoto Nakahama, MD, Ysuke Kawai, MD, Mitsuru Munemasa, MD, Natsuki Takahashi, MD, Naoki Mukohara, MD, Seiji Habara, MD, Yusuke Katayama, MD, Ritsuko Terasaka, MD, Atsushi Mima, MD, Hitoshi Matsubara, MD, Shingo Hosogi, MD, Masayuki Doi, MD, Masayuki Ueeda, MD, Norio Urabe, MD, Kazufumi Takeuchi, MD, Yasuharu Namba, MD, Tetsuya Sato, MD, Nobuyuki Yamada, MD, Masahito Taniguchi, MD, Yutaka Kajikawa, MD, Kouki Watanabe, MD, Kenichi Hisamatsu, MD, Hiroo Kobayashi, MD, and Kiyoaki Maekawa, $\mathrm{MD}$, who were the PEACH investigators. We thank Kaoru Akazawa, Miyuki Fujiwara, and Masayo Ohmori for their technical assistance. This study was funded by the Japan Heart Foundation (No. 12090021).

\section{References}

1. Tsimikas S and Hall JL: Lipoprotein(a) as a potential causal genetic risk factor of cardiovascular disease: a rationale for increased efforts to understand its pathophysiology and develop targeted therapies. J Am Coll Cardiol (2012) 60: 716-721.

2. Schmidt $K$, Noureen $A$, Kronenberg $F$ and Utermann G: Structure, function, and genetics of lipoprotein(a). J Lipid Res (2016) 57: 1339-1359.

3. Erqou S, Kaptoge S, Perry PL, Di Angelantonio E, Thompson A, White IR, Marcovina SM, Collins R, Thompson SG and Danesh J: Lipoprotein(a) concentration and the risk of coronary heart disease, stroke, and nonvascular mortality. JAMA (2009) 302: 412-423.

4. Clarke R, Peden JF, Hopewell JC, Kyriakou T, Goel A, Heath SC, Parish S, Barlera S, Franzosi MG, Rust S, Bennett D, Silveira A, Malarstig A, Green FR, Lathrop M, Gigante B, Leander K, de Faire U, Seedorf U, Hamsten A, Collins R, Watkins $\mathrm{H}$ and Farrall $M$ : Genetic variants associated with $L p(a)$ lipoprotein level and coronary disease. N Engl J Med (2009) 361: 2518-2528.

5. Kamstrup PR, Tybjaerg-Hansen A, Steffensen R and Nordestgaard BG: Genetically elevated lipoprotein(a) and increased risk of myocardial infarction. JAMA (2009) 301: 2331-2339.

6. Kotani K, Serban MC, Penson P, Lippi G and Banach M: Evidence-based assessment of lipoprotein(a) as a risk biomarker for cardiovascular diseases - Some answers and still many questions. Crit Rev Clin Lab Sci (2016) 53: 370-378.

7. Osawa K, Nakanishi R and Budoff M: Coronary Artery Calcification. Global heart (2016) 11: 287-293.

8. Detrano R, Guerci AD, Carr JJ, Bild DE, Burke G, Folsom AR, Liu K, Shea S, Szklo M, Bluemke DA, O'Leary DH, Tracy R, Watson K, Wong ND and Kronmal RA: Coronary calcium as a predictor of coronary events in four racial or ethnic groups. N Engl J Med (2008) 358: 1336-1345.

9. Raggi $P$, Callister $T Q$ and Shaw LJ: Progression of coronary artery calcium and risk of first myocardial infarction in patients receiving cholesterol-lowering therapy. Arterioscler Thromb Vasc Biol (2004) 24: 1272-1277.

10. McEvoy JW, Blaha MJ, Defilippis AP, Budoff MJ, Nasir K, Blumenthal RS and Jones SR: Coronary artery calcium progression: an important clinical measurement? A review of published reports. J Am Coll Cardiol (2010) 56: 1613-1622.

11. Budoff MJ, Hokanson JE, Nasir K, Shaw LJ, Kinney GL, Chow D, Demoss D, Nuguri V, Nabavi V, Ratakonda R, Berman DS and Raggi P: Progression of coronary artery calcium predicts all-cause mortality. JACC Cardiovascular imaging (2010) 3: 1229-1236.

12. Miyoshi $\mathrm{T}$, Kohno $\mathrm{K}$, Asonuma $\mathrm{H}$, Sakuragi $\mathrm{S}$, Nakahama $\mathrm{M}$, Kawai $Y$, Uesugi T, Oka T, Munemasa M, Takahashi N, Mukohara N, Habara S, Koyama Y, Nakamura K and Ito H: Effect of Intensive and Standard Pitavastatin Treatment With or Without Eicosapentaenoic Acid on Progression of Coronary Artery Calcification Over 12 Months- Prospective Multicenter Study. Circ J (2018) 82: 532-540.

13. Qasim AN, Martin SS, Mehta NN, Wolfe ML, Park J, Schwartz S, Schutta M, Iqbal N and Reilly MP: Lipoprotein(a) is strongly associated with coronary artery calcification in type-2 diabetic women. Int J Cardiol (2011) 150: 17-21.

14. Sung KC, Wild SH and Byrne CD: Lipoprotein(a), metabolic syndrome and coronary calcium score in a large occupational cohort. Nutrition, metabolism, and cardiovascular diseases: Nutr Metab Cardiovasc Dis (2013) 23: 1239-1246.

15. Sugiyama H, Miyoshi T, Osawa K, Miki T, Koide $\mathrm{Y}$, Nakamura K, Morita $\mathrm{H}$ and Ito $\mathrm{H}$ : Serum cystatin $\mathrm{C}$ levels are associated with coronary artery calcification in women without chronic kidney disease. J Cardiol (2017) 70: 559-564. 
16. Agatston AS, Janowitz WR, Hildner FJ, Zusmer NR, Viamonte M, Jr. and Detrano R: Quantification of coronary artery calcium using ultrafast computed tomography. J Am Coll Cardiol (1990) 15: 827832.

17. Standards of medical care in diabetes--2008. Diabetes Care (2008) 31 Suppl 1: S12-54.

18. Kotani K, Yamada S, Yamada T, Kario K and Taniguchi N: Oxidized lipoprotein(a) and cardio-ankle vascular index (CAVI) in hypertensive subjects. Heart vessels (2013) 28: 461-466.

19. Khera AV, Everett BM, Caulfield MP, Hantash FM, Wohlgemuth J, Ridker PM and Mora S: Lipoprotein(a) concentrations, rosuvastatin therapy, and residual vascular risk: an analysis from the JUPITER Trial (Justification for the Use of Statins in Prevention: an Intervention Trial Evaluating Rosuvastatin). Circulation (2014) 129: $635-642$.

20. Anderson TJ, Gregoire J, Pearson GJ, Barry AR, Couture P, Dawes M, Francis GA, Genest J, Jr., Grover S, Gupta M, Hegele RA, Lau DC, Leiter LA, Lonn E, Mancini GB, McPherson R, Ngui D, Poirier P, Sievenpiper JL, Stone JA, Thanassoulis G and Ward R: 2016 Canadian Cardiovascular Society Guidelines for the Management of Dyslipidemia for the Prevention of Cardiovascular Disease in the Adult. Can J Cardiol (2016) 32: 1263-1282.

21. Guan W, Cao J, Steffen BT, Post WS, Stein JH, Tattersall MC,
Kaufman JD, McConnell JP, Hoefner DM, Warnick R and Tsai MY: Race is a key variable in assigning lipoprotein(a) cutoff values for coronary heart disease risk assessment: the Multi-Ethnic Study of Atherosclerosis. Arterioscler Thromb Vasc Biol (2015) 35: 9961001.

22. Tsimikas S: A Test in Context: Lipoprotein(a): Diagnosis, Prognosis, Controversies, and Emerging Therapies. J Am Coll Cardiol (2017) 69: 692-711.

23. Nielsen LB, Gronholdt ML, Schroeder TV, Stender $S$ and Nordestgaard BG: In vivo transfer of lipoprotein(a) into human atherosclerotic carotid arterial intima. Arterioscler Thromb Vasc Biol (1997) 17: 905-911.

24. Seimon TA, Nadolski MJ, Liao X, Magallon J, Nguyen M, Feric NT, Koschinsky ML, Harkewicz R, Witztum JL, Tsimikas S, Golenbock D, Moore KJ and Tabas I: Atherogenic lipids and lipoproteins trigger CD36-TLR2-dependent apoptosis in macrophages undergoing endoplasmic reticulum stress. Cell Metab (2010) 12: 467-482.

25. Cho JH, Lee da Y, Lee ES, Kim J, Park SE, Park CY, Lee WY, Oh KW, Park SW and Rhee EJ: Increased risk of coronary artery calcification progression in subjects with high baseline Lp(a) levels: The Kangbuk Samsung Health Study. Int J Cardio (2016) 222: 233-237. 